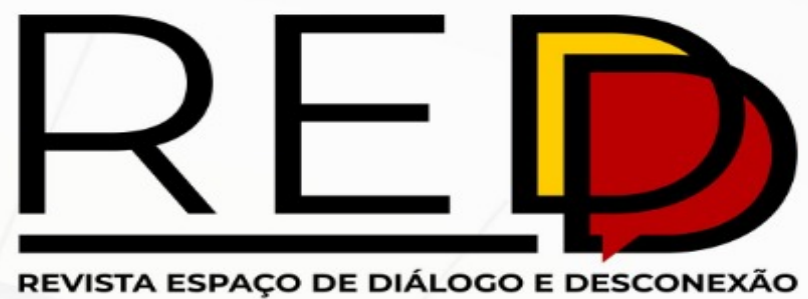

Link: https://periodicos.fclar.unesp.br/redd/index

\title{
Higiene e AdequaÇÃo no PNAE de ARARAQUARA/SP: ANÁlise SOB A PERSPECTIVA da GeStão
}

\author{
Lázaro Velasco Borges¹; Helena Carvalho De Lorenzo²; Maria Lúcia Ribeiro ${ }^{3}$. \\ ${ }^{1}$ ID ORCID: ${ }^{1}$ https://orcid.org/0000-0001-7427-9882; ${ }^{2}$ https://orcid.org/0000-0002-7744-0157; ${ }^{3}$ https://orcid.org/0000-0002-3654-8831
}

Autor para correspondência e-mail: lazarovborges@yahoo.com.br

\section{Palavras-chave}

Segurança Alimentar e

Nutricional

Higiene

Adequação

Políticas Públicas

PNAE

\section{Keywords}

Food and Nutrition Security

Hygiene

Adequacy

Public Policies

PNAE

\section{Palabras clave}

Seguridad Alimentaria y

Nutricional

La higiene

La adecuación

Políticas públicas

PNAE

\section{RESUMO}

O objetivo deste artigo é avaliar se a política pública do Programa Nacional de Alimentação Escolar (PNAE) executada no Município de Araraquara/SP atende as exigências estabelecidas pela Food and Agriculture Organization (FAO) e demais instâncias governamentais no que tange à higiene alimentar e adequação às normas técnicas observando as ações da gestão local. Este estudo de caso foi realizado a partir da observação de campo e entrevistas semiestruturadas desenvolvidas a partir do General Principles of Food Hygiene, elaborado pela FAO, da legislação vigente e de documentos oficiais que normatizam a temática, num conjunto único e adaptado à realidade do PNAE, que permitem analisar pontos cruciais da organização. $\mathrm{O}$ estudo classificou a execução do PNAE no município como alta, contudo, existem problemas a serem solucionados e o caminho inicial seria repensando a estrutura da política pública. Dessa forma, buscou-se contribuir para o estudo da SAN no que tange à higiene e adequação dos alimentos oferecidos ao alunato.

\section{Abstract \\ HYgIENE AND FITNESS AT ARARAQUARA'S/SP PNAE: ANALYSIS UNDER MANAGEMENT'S PERSPECTIVE}

The objective of this article is to evaluate whether the public policy of the National School Feeding Program (PNAE) implemented in the Municipality of Araraquara/SP meets the requirements established by the Food and Agriculture Organization (FAO) and other governmental bodies with regard to food hygiene and adequacy technical standards observing the actions of local management. This case study was carried out from the field observation and semi-structured interviews developed from the General Principles of Food Hygiene, prepared by FAO, of the current legislation and official documents that regulate the thematic, in a single set and adapted to the reality of the PNAE, which allow you to analyze crucial points of the organization. The study classified the execution of PNAE in the municipality as high, however, there are problems to be solved and the initial path would be to rethink the structure of public policy. Thus, we sought to contribute to the study of SAN in relation to the hygiene and adequacy of food offered to the students.

\section{RESUMEN \\ Higiene e Adecuación EN El PNAE de ARARAQUARa/SP: ANÁlisis bajo la PERSPEC- TIVA DE LA GESTIÓN \\ El objetivo de este artículo es evaluar si la política pública del Programa Nacional de Alimentación Escolar (PNAE) ejecutada en el Municipio de Araraquara/SP atiende las exigencias establecidas por la Food and Agriculture Or- ganization (FAO) y demás instancias gubernamentales en lo que se refiere a la higiene alimentaria y adecuación a las normas técnicas observando las acciones de la gestión local. Este estudio de caso fue realizado a partir de la observación de campo y entrevistas semiestructuradas desarrolladas a partir del General Principles of Food Hy- giene, elaborado por la FAO, de la legislación vigente y de documentos oficiales que normalizan la temática, en un conjunto único y adaptado a la realidad del PNAE, que permiten analizar puntos cruciales de la organización. El estudio clasificó la ejecución del PNAE en el municipio como alta, sin embargo, existen problemas a ser soluciona- dos y el camino inicial sería repensando la estructura de la política pública. De esta forma, se buscó contribuir al estudio de la SAN en lo que se refiere a la higiene y adecuación de los alimentos ofrecidos al alunato.}




\section{INTRODUÇ̃̃o}

O conceito de Segurança Alimentar e Nutricional (SAN) é uma construção histórica baseada no Direito Humano à Alimentação Adequada (DHAA) a partir do artigo 25 da Declaração Universal dos Direitos Humanos, assim descrito:

Art. 25. Todos os seres humanos têm direito a um padrão de vida capaz de assegurar a saúde e bemestar de si mesmo e da sua família, inclusive alimentação, vestuário, habitação, cuidados médicos e os serviços sociais indispensáveis, e direito à segurança em caso de desemprego, doença, invalidez, viuvez, velhice ou outros casos de perda dos meios de subsistência fora do seu controle (ONU, 1948, p. 12).

Especificamente, quando observamos a literatura acadêmica sobre o assunto é possível constatar que os estudos apontam que, práticas inadequadas de higiene, processamento de alimentos, falta de infraestrutura física adequada e profissionais inabilitados fornecem riscos potenciais de contaminação dos alimentos, o que constitui um problema de saúde pública (SANTOS; SANTOS, 2016).

Levando em consideração que o conceito de SAN preconiza não somente a disponibilidade e quantidade, mas também a higiene, saúde e meio ambiente como parâmetros a serem alcançados (FAO, 1992), podemos deduzir que os mecanismos de avaliação da política pública deveriam dedicar atenção sobre estes aspectos.

O Programa Nacional de Alimentação Escolar (PNAE) exige o cumprimento de normas e exerce a fiscalização e controle dos alimentos oferecidos aos estudantes, contudo, não existe na legislação vigente um instrumento que auxilie os gestores públicos no cruzamento das informações sobre a situação real dos alimentos para, posteriormente, monitorar os resultados obtidos.

As políticas públicas no Brasil são objetos de estudos há décadas motivados pela visão do Estado como promotor do bem-estar social. Diante deste cenário, a educação possui papel fundamental como componente estrutural da sociedade, tornando a escola tema central em diversos trabalhos acadêmicos numa gama extensa de áreas de pesquisa, nos quais destacamos a alimentação escolar.

Considerando a importância deste tema, a política pública de SAN focada na alimentação escolar através do PNAE ganha destaque, pois as unidades de ensino, em todas as esferas governamentais são promotoras da alimentação oferecida ao alunato, o que impõe ao Poder Público a responsabilidade de garantir que os alimentos possuam condições mínimas de aptidão para o consumo.

Em paralelo ao exposto anteriormente, ainda é possível notar o distanciamento dos conceitos de higiene e adequação ao analisar as metas estipuladas para o PNAE presentes no Plano Nacional de Segurança Alimentar e Nutricional (PLANSAN) 2016-2019 que se resumem ao número de estudantes atendidos, sem sequer mencionar os demais critérios que superam a dimensão da abrangência e quantidade.

Diante de tal cenário, esta pesquisa busca avaliar o PNAE no Município de Araraquara/SP a partir de elementos que demonstrem o cumprimento das diretrizes da política pública de SAN, no que tange à higiene (condições higiênico-sanitárias apropriadas que garantam a segurança do alimento para o consumo), e adequação (normas técnicas dispostas sobre a gestão, produção e manipulação dos alimentos em todas as etapas), a partir da observação das ações da gestão local.

\section{Segurança Alimentar e Nutricional, Alimentação Escolar e Higiene: Conceitos e Traje- TÓRIAS}

A preocupação com a Segurança Alimentar surge como objeto de discussão a partir da Primeira Guerra Mundial (1914-1918). O entendimento consolidado era de estrita ligação à soberania nacional visto como a capacidade de cada país alcançar sua autossuficiência alimentar de modo a não se tornar vulnerável a escassez de alimentos nos momentos de crise.

O tema volta a ser discutido com o advento da Segunda Guerra Mundial (1939-1945) quando os países europeus sofreram crises graves de desabastecimento como consequências do conflito. Em suma, as políticas de SAN dos países desenvolvidos voltavam-se para a sustentação e estocagem de produtos estratégicos com caráter preventivo assegurando a oferta de alimentos e de renda para os agricultores (PAULILLO; PESSANHA, 2002).

A partir da constituição da Organização das Nações Unidas (ONU) em 1945, o conceito passou a ser discutido em meio a interesses divergentes. A tensão política concentrou-se entre os organismos que entendiam 
a Segurança Alimentar como direito humano em contraponto a corrente que atribuía essa garantia aos mecanismos de mercado.

Esse período de intensificação da produção agrícola mundial decorreu da adoção de variedades híbridas e de alto rendimento que ameaçou a herança genética oriunda da diversidade das espécies alimentares, uma vez que o controle sobre o genoma passou a ser gerenciado por grupos econômicos que fortaleceram os direitos sobre a propriedade industrial e intelectual colocando em risco o livre acesso à base genética das culturas (PAULILLO; PESSANHA, 2002).

Contudo, o acesso à alimentação constitui-se como uma garantia atrelada ao próprio direito fundamental à dignidade humana, sendo que sua negação por qualquer motivo nega a condição fundamental para o exercício da cidadania, que é a própria vida (MALUF; MENEZES; VALENTE, 1996). Dessa forma, a SAN necessita do fortalecimento dos direitos de cidadania das camadas mais sensíveis e vulneráveis da população (PAULILLO; PESSANHA, 2002).

Com a percepção desta nova dimensão do problema, no final da década de 80 e o início da década de 90 , o conceito de Segurança Alimentar passa a incorporar também a noção de alimentos seguros (livres de contaminação química e biológica), de qualidade (nutricional, biológica, sanitária e tecnológica), produzidos sob aspectos de sustentabilidade, respeitando a diversidade cultural e com ampla visibilidade à população. Esta mudança foi ratificada nas Declarações da Conferência Internacional de Nutrição, realizada em Roma, em 1992, pela FAO e pela Organização Mundial da Saúde (OMS).

Assim, o estudo da temática envolvendo a higiene e adequação às normas técnicas referentes à gestão da política pública ganhou relevância conforme a ideia de SAN incorporou novas dimensões de significados ao longo do tempo.

Conceitualmente, a segurança dos alimentos está associada aos corretos e adequados processos de produção e de manuseio dentro de toda cadeia produtiva de alimento, desde a produção primária até o ponto de consumo, uma vez que sé dessa forma se torna possível o controle efetivo dos contaminantes e perigos à saúde (MARTINS; QUARENTEI, 2013).

Diante deste cenário, os governos passaram a adotar regras, regulamentos e normas técnicas aplicadas "[...] sobre bens produzidos internamente e sobre importados, com objetivo de garantir padrões de qualidade, de segurança, de proteção à saúde e ao meio ambiente" (ORTEGA; BORGES, 2015, p. 74).

Contudo, para evitar que este novo arcabouço de regras fosse utilizado para a realização de práticas abusivas ao comércio internacional, considerando a redução de tarifas e as pressões políticas para a adoção de medidas protecionistas aos setores menos competitivos, a Organização Mundial do Comércio (OMC) adota o Codex Alimentarius como referencial para que os países membros implementem medidas sanitárias para seus alimentos, "[...] pois, entre outros objetivos, o Codex propõe orientar e promover a elaboração e a definição de requisitos para auxiliar na harmonização de normas alimentares e com isso facilitar o comércio internacional" (ORTEGA; BORGES, 2015, p. 75).

A partir deste momento, percebe-se que a ótica da qualidade ganha destaque na comunidade internacional, pois a melhoria dos produtos proporciona o alcance a novos mercados e atende à complexidade dos consumidores que passam a exigir mais garantias na integridade física, química e biológica dos alimentos.

O Codex Alimentarius, para organizar a implementação de medidas sanitárias pelos países membros elabora códigos que definem "[...] as práticas de produção, elaboração, manufatura, transporte e armazenamento de alimentos ou grupos de alimentos determinados, para garantir a inocuidade e a aptidão dos alimentos para o consumo" (ORTEGA; BORGES, 2015, p. 77).

Inserida neste contexto, a Alimentação Escolar é considerada um pilar estrutural na política de SAN, dada a importância da alimentação adequada para o desenvolvimento físico-intelectual de seu público-alvo (AGUIAR, 2011).

As iniciativas governamentais na alimentação escolar no País começaram na década de 1930, quando alguns estados e municípios mais ricos passaram a responsabilizar-se pelo fornecimento da alimentação em sua rede de ensino, ou seja, as primeiras intervenções ocorreram de forma individualizada e sem amplitude no território nacional. A preocupação era com a desnutrição infantil, resultado de uma somatória de fatores fisiológicos (desnutrição de grávidas, lactantes e crianças) e sociais (qualidade de vida das famílias) e econômicos (relacionados à renda e acesso aos alimentos) (CARVALHO; CASTRO, 2009). 
Novas ações ganharam repercussão na década de 50 como Programa Nacional de Merenda Escolar (PNME), sob a responsabilidade da CNA. O Decreto nº. 37.106/1955, formalizou o PNME/CNA como Campanha Nacional de Alimentação Escolar (CNAE), com a distribuição de alimentos (leite em pó + vitaminas A e D lipossolúveis) doados pelo Fundo Internacional de Socorro à Infância (FISI) aos estados mais pobres. O FISI tinha como objetivo diminuir a desnutrição de países da América Latina, entre eles o Brasil. Posteriormente o programa se nacionalizou, e as doações passaram a ser feitas pela United States Agency for International Development (USAID), com a inclusão de novos produtos doados e comprados com preços mais baixos (CARVALHO; CASTRO, 2009).

No início da década de 1970, a ajuda alimentar internacional diminui, o que colaborou para a instalação das primeiras indústrias alimentícias brasileiras, contudo, os cardápios eram pobres em qualidade e sabor, e visavam apenas desenvolver as indústrias nacionais do ramo, fortemente asseguradas por esse mercado governamental (COIMBRA, 1982 apud CARVALHO; CASTRO, 2009).

O PNAE foi criado em 1979, mas somente com a promulgação da CF/88, foi assegurado o direito à alimentação escolar a todos os alunos do ensino fundamental, como programa suplementar à política educacional (CARDOSO; SOUZA; SANTOS, 2005).

A partir da década de 90, o Estado brasileiro assumiu, como prioridade, assegurar a educação para todos e incluiu o PNAE, juntamente com os programas de Distribuição de Material Didático-Escolar, de Assistência à Saúde e de Transporte, como medidas para facilitar ao escolar o desenvolvimento do alunato nos estudos (VIEIRA et. al., 2008).

Especificamente, o PNAE passou por diversas transformações que ampliaram sua capacidade de gestão. A primeira transformação ocorreu com a promulgação da Lei no 8.913 de 1994, que possibilitou a administração descentralizada do programa permitindo "[...] racionalizar a logística e os custos de distribuição dos produtos, além de viabilizar o oferecimento de uma alimentação condizente com o hábito alimentar da população nas diferentes localidades do país" (PEIXINHO, 2013, p. 911).

Em 1999, o repasse de recursos financeiros ao PNAE passou a ocorrer por transferência direta e automática, incluindo todos os municípios, Distrito Federal (DF) e estados no recebimento de verbas para aquisição de gêneros alimentícios.

Ainda neste período, o Governo Federal estabeleceu que, o repasse de verbas para os entes federados para aquisição de gêneros alimentícios fica condicionado à existência obrigatória dos Conselhos de Alimentação Escolar (CAE).

Com a instituição do Programa Fome Zero, em 2003, durante o Governo Lula, o PNAE passa a integrar o bojo de políticas de acesso aos alimentos e inaugura uma nova sucessão de avanços na sua gestão. Podemos relacionar entre as novas medidas a "[...] ampliação e fortalecimento do papel do CAE no controle social e as estratégias normativas para as ações do nutricionista como Responsável Técnico" (PEIXINHO, 2013, p. 912).

Neste período, o programa incorporou também alguns princípios norteadores para sua execução tais como: equidade, participação social, universalidade, sustentabilidade/continuidade, compartilhamento de responsabilidades, direito humano à alimentação adequada e respeito aos hábitos e tradições regionais (PEIXINHO, 2013).

Com a promulgação da Lei $n^{\circ} 11.947$, de 16 de junho de 2009, o PNAE torna-se universal para toda educação básica, além de jovens e adultos; inclui a educação alimentar e nutricional como eixo prioritário dos objetivos do programa; fortalece a participação popular na gestão; formaliza a continuidade no repasse de verbas mesmo nas hipóteses em que ocorrem irregularidades na execução do programa.

A Resolução no 26, do FNDE, de 17 de junho de 2013, incluiu a orientação que o cardápio da alimentação escolar seja elaborado por nutricionista habilitado, que deve assumir a responsabilidade técnica do programa, com o acompanhamento do Conselho de Alimentação Escolar (CAE) e as refeições devem atender 30\% (trinta por cento) das necessidades nutricionais diárias dos alunos das creches e escolas indígenas e das situadas em áreas remanescentes de quilombos, sendo que, no caso dos alunos matriculados em creches, pré-escolas e escolas do ensino fundamental, o cardápio deve suprir 15\% das necessidades nutricionais diárias, durante as atividades em sala de aula (BRASIL, 2013; VIEIRA et. al, 2008).

Em 2007, foram construídos os Centros Colaboradores em Alimentação e Nutrição Escolar (CECANE), através da parceria entre o FNDE e Instituições Federais de Ensino Superior com o objetivo de ampliar e garantir a melhoria da execução do PNAE, formando assim centros de ensino, pesquisa e extensão atuantes nas 
cinco regiões geográfica do Brasil.

Diante do exposto podemos afirmar que as políticas de alimentação escolar tiveram sua importância reconhecida tornando-se uma política pública de abrangência nacional que, ao longo do tempo, aperfeiçoou-se para incorporar dimensões e realidades diferentes na oferta de refeições ao alunato.

A questão que traz convergência para a compreensão da relação entre a gestão e os demais agentes que articulam o PNAE em torno da qualidade do alimento encontra-se no artigo 33 da Resolução FNDE n 26, de 17 de junho de 2013, assim descrito:

Art. 33 Os produtos alimentícios a serem adquiridos para o alunado do PNAE deverão atender ao disposto na legislação de alimentos, estabelecida pela Agência Nacional de Vigilância Sanitária - ANVISA do Ministério da Saúde - MS e pelo Ministério da Agricultura, Pecuária e Abastecimento - MAPA.

Este dispositivo determina que os produtos alimentícios adquiridos para o PNAE devematender à legislação de alimentos elaborada pela ANVISA, MSe MAPA, ou seja, todos os parâmetros balizadores da higiene e adequação do alimento aplicam-se nesta etapa da gestão, sendo expressamente previsto que as unidades executoras do programa são obrigadas a adotar medidas que garantam a aquisição, o transporte, a estocagem, e o preparo/manuseio de alimentos com adequadas condições higiênico-sanitárias até o consumo pelos beneficiários (BRASIL, 2013).

Assim, o PNAE exige que sua gestão integre produção e manipulação, desde o campo até a escola, de forma que todos os agentes estejam em adequação com a legislação nacional e internacional.

Dessa forma, torna-se claro que a política pública busca a distribuição de alimentação saudável ao alunato, tanto em relação aos fatores nutricionais quanto à adequação as condições higiênico-sanitárias dos gêneros alimentícios.

\section{MATERIAIS E Métodos}

A pesquisa foi realizada no Município de Araraquara, situado na Região Administrativa Central do Estado de São Paulo. Segundo os dados disponíveis na Fundação Sistema Estadual de Análise de Dados (SEADE), a municipalidade conta, em 2018, com população estimada de 224.389 mil habitantes numa localidade que perfaz a área de 1.000,63 $\mathrm{km}^{2}$.

Analisando os dados sobre a escolaridade, o Índice Paulista de Responsabilidade Social (IPRS) realizado em 2014 atribuiu valor de 60 ao Município, o que superou a avaliação do Estado de São Paulo, no valor de 54, demonstrando indícios sobre a presença de avanços nas políticas educacionais da localidade.

Sobre a riqueza, o IRPS do Município, no mesmo período, ficou em 44, abaixo da média estadual de 47 e, na longevidade, a avaliação da Municipalidade foi de 69 contra a média estadual no valor de 70 . Estes números indicam que o Município de Araraquara apresenta condições aceitáveis de vida para a população.

Como o foco da pesquisa reside sobre a execução do PNAE, discutiremos a situação do alunato municipal na perspectiva do programa. Segundo dados do PNAE, em 2018, o Município de Araraquara/SP atendeu cerca de 18.501 mil alunos matriculados na rede de ensino, como dispostos na Tabela 01.

Tabela 01 - alunos atendidos pelo PNAE no município de Araraquara em 2018.

\begin{tabular}{c|c}
\hline UNIDADES & QUANTIDADE \\
\hline Creches & 5745 \\
\hline Pré-Escola & 4515 \\
\hline Ensino Fundamental & 7482 \\
\hline Ensino Médio & 0 \\
\hline Fundamental EJA & 460 \\
\hline Médio EJA & 0 \\
\hline $\begin{array}{c}\text { Atendimento Educacional Especializa- } \\
\text { do (AEE) }\end{array}$ & 299 \\
\hline
\end{tabular}

Fonte: PNAE (2018). 
A estratégia utilizada foi o estudo de caso pois ele permite analisar um determinado cenário "[...] quando o pesquisador tem pouco controle sobre os acontecimentos e quando o foco se encontra em fenômenos contemporâneos inseridos em algum contexto da vida real" (YIN, 2005, p. 19).

O grande diferencial do estudo de caso para o objeto desta pesquisa é sua capacidade de lidar com uma ampla variedade de fontes de dados além da disponibilidade de estudo histórico convencional (YIN, 2005).

Nesta pesquisa, as fontes secundárias de dados foram obtidos na Prefeitura Municipal de Araraquara/SP e por meio eletrônico em sites institucionais como Fundação Sistema Estadual de Análise de Dados (SEADE), Fundo Nacional do Desenvolvimento da Educação (FNDE), Empresa Brasileira de Pesquisa Agropecuária (EMBRAPA), Agência Nacional de Vigilância Sanitária (ANVISA), Ministério da Agricultura, Pecuária e Abastecimento (MAPA), Instituto Brasileiro de Geografia e Estatística (IBGE) entre outros.

Os dados de fonte primária foram obtidos por meio de exploração em campo e entrevistas semiestruturadas com os agentes responsáveis pela execução do programa. As entrevistas tiveram por objetivo verificar se ocorre o cumprimento das exigências propostas tanto nas diretrizes do PNAE quanto na documentação elaborada pela $\mathrm{FAO} / \mathrm{ONU}$ e seus desdobramentos, que trata sobre a higiene dos alimentos e a adequação às normas técnicas de gestão, produção e manipulação dos alimentos.

A partir desta documentação foram criadas questões organizadas em blocos temáticos sendo atribuídos pesos ( $\mathrm{k}$, igual a 15, 20, 25 ou 30) de acordo com o grau de relevância.

O grau de relevância, por sua vez, foi atribuído seguindo dois critérios: (a) o objeto da pesquisa e (b) a importância das práticas agrupadas na categoria para o alcance de padrões satisfatórios de higiene conforme a legislação vigente (adequação normativa), conforme a Tabela 02:

Tabela 02 - a $^{\text {a }}$ ategoria: Gestão Local.

\begin{tabular}{lll}
\hline BLOCO & TEMA & PESO \\
\hline 01 & Estrutura Organizacional e Administrativa & 15 \\
02 & Elaboração dos Cardápios & 20 \\
03 & Aquisição de Gêneros Alimentícios & 20 \\
04 & Controle e Qualidade dos Alimentos & 30 \\
05 & Conselho de Alimentação Escolar & 15 \\
\hline
\end{tabular}

Fonte: Autor (2019).

A pontuação para cada questão avaliada será atribuída de acordo com o seguinte critério:

a) Insatisfatório (nota 1): será atribuído quando o quesito não é cumprido em sua totalidade;

b) Parcialmente Satisfatório (nota 3): será atribuído quando o quesito for parcialmente atendido ou cumprido por outros meios não previstos;

c) Satisfatório (nota 5): será atribuído quando o quesito for cumprido em sua totalidade.

Para o cálculo dos pontos obtidos em cada bloco da lista de verificação é aplicada a fórmula:

$\mathrm{PBx}=(\Sigma \mathrm{x} / \mathrm{Px}) \cdot \mathrm{kx}$

Onde:

PBx: Pontuação alcançada no bloco X (1 a 5)

$\sum \mathrm{x}$ : Somatório das notas obtidas nos itens do bloco $\mathrm{X}$

Px: Pontuação máxima possível no bloco X

kx: Peso atribuído ao bloco X

Esta fórmula é uma adaptação do modelo matemático aplicado ao método de avaliação da CECANE, assim disposto:

$\mathrm{PBx}=(\Sigma \mathrm{x} / \mathrm{Px}-\Sigma \mathrm{NAx}) . \mathrm{kx}$ 
Onde:

PBx: Pontuação alcançada no bloco X (1 a 5)

$\sum \mathrm{x}$ : Somatório das notas obtidas nos itens do bloco $\mathrm{X}$

Px: Pontuação máxima possível no bloco X

¿NAx: Somatório das notas das questões não aplicáveis no bloco

kx: Peso atribuído ao bloco X

A justificativa para a exclusão da variável $\Sigma \mathrm{NAx}$ do modelo adaptado nesta pesquisa reside sobre o fato de que o modelo original da CECANE estabelece uma pontuação prévia a cada item avaliado. No modelo proposto neste projeto de pesquisa, a pontuação será aplicada de acordo com as respostas oferecidas, sendo viável neste caso, excluir a questão não aplicável e justificando sua ausência de acordo com a necessidade.

Após o cálculo de pontos obtidos em cada um dos blocos (PB), os resultados obtidos são somados.

Após a análise dos dados, estes serão classificados por blocos que permitirá a comparação entre os resultados da mesma espécie e por pontuação total da seguinte forma:

Muito Baixa (0 - 25 pontos);

Baixa (26 50 pontos);

Regular (51 - 75 pontos);

Alta (76 - 90 pontos);

$\square$ Muito Alta (91 - 100 pontos).

Vale ressaltar que, caso ocorra um resultado fracionado, sendo este equivalente a 0,5 ou superior, será arredondado para cima, para fins de resultado.

Após a avaliação, os agentes identificados como adequação "muito baixa" ou "baixa" oferecem elementos de que a execução do PNAE pelo Município não cumpre com as exigências necessárias para garantir a higiene dos alimentos e adequação às normas técnicas. Os demais itens devem ser avaliados e as prioridades indicadas para correção de acordo com as conclusões elaboradas pela pesquisa.

Quanto às ferramentas de pesquisa foram utilizadas entrevistas semiestruturadas acompanhadas de gravação de áudio, se autorizadas pelo entrevistado, bem como a transcrição de suas falas.

\section{DESCRIÇÃO DOS DADOS}

A entrevista foi conduzida com a responsável técnica (RT) pela gestão do PNAE no município de Araraquara/SP e os membros do Conselho de Alimentação Escolar (CAE) de acordo com os blocos de questões elaborados a partir da Resolução FNDE n 26 de 17 de junho de 2013 e da Resolução FNDE nº 2, de 02 de abril de 2015 e constantes do Apêndice I deste trabalho.

No bloco 1, referente a estrutura organizacional e administrativa do PNAE, foi relatado que o município conta com uma estrutura adequada e suficiente para a execução da política, porém, existe um déficit significativo de nutricionistas disponíveis que prejudicam algumas atividades específicas do programa. Segundo o relato, o município conta com 02 (dois) nutricionistas, onde deveria ter um número maior que 20 (vinte), de acordo com o exigido pela Resolução CFN nº 465/2010.

A consequência mais direta desta defasagem de nutricionistas recaí sobre a RT pois, ela concentra em si as atribuições técnicas da nutricionista juntamente com as funções de gestora do programa como abastecimento, visitas técnicas, processos de compras, entre outras atividades.

O bloco 2 observou a elaboração dos cardápios. Estes são idealizados a partir dos princípios da alimentação saudável, priorizando a inserção de alimentos in natura, oriundos especialmente da agricultura familiar, porém, com pouca presença de orgânicos.

Isso revela que a agricultura no modelo convencional predomina nos alimentos adquiridos para o PNAE, mas a RT afirma que o município realiza um controle bem grande no uso de agrotóxicos nessa produção" sem 
especificar quais são os mecanismos utilizados.

O município não conta com cardápios que consideram a culinária regional, seguindo o padrão básico de alimentação da população do Estado de São Paulo em sua elaboração.

A RT apontou que a elaboração dos cardápios considera o período frequentado pelo aluno para cumprir o que a legislação preconiza quanto aos parâmetros nutricionais a serem atingidos, contudo, ela relata que existe uma dificuldade de alcançar o que é definido pela Resolução FNDE nª 26/2013 no que se refere aos macro/ micro nutrientes e, principalmente, fibras. A princípio, esse problema ocorre pela aceitação dos alimentos oferecidos que são condicionados pelos hábitos alimentares do alunato.

A análise do período de aulas também é crucial para determinar a quantidade de refeições servidas na rede de ensino, de acordo com a legislação.

O município oferece atenção às crianças com necessidades especiais através do fornecimento de alimentos próprios para cada problema, mediante comprovação da família já que o município não conta com especialistas disponíveis para a identificação do caso na rede educacional. Quando a situação é identificada, o setor toma as providências para garantir os alimentos necessários e passa todas as instruções para os agentes sociais (merendeiras), diretores e familiares de como proceder com a alimentação da criança.

Os cardápios são publicados em locais visíveis e de fácil acesso, sendo que na educação infantil ele é exposto com ilustrações afim de atrair a atenção do alunato, porém, ainda não existe a possibilidade de consulta por meio eletrônico, o que está em processo de estruturação pelo município.

O município conta com um manual de alimentação escolar que possui informações sobre os conceitos de alimentação, contaminação, boas práticas, além de um ciclo de treinamento no dia-a-dia sobre os cardápios, suas atribuições, os riscos no preparo e as ações que devem ser desenvolvidas para evitar seu acontecimento.

Contudo, o município não possui o receituário padrão e a receita técnica de preparo das receitas porque não possui condições administrativas para elaborá-lo.

No bloco 3 foi analisado o processo de aquisição de gêneros alimentícios para o PNAE.

Segundo o relato, o recurso financeiro do PNAE supre uma média de $20 \%$ a $22 \%$, do custo anual da alimentação escolar no município e o recurso é utilizado exclusivamente para a aquisição de gêneros alimentícios. Alimentos proibidos não são adquiridos com o PNAE nem com recursos próprios da municipalidade.

Dos recursos advindos do PNAE, o município preocupa-se com a aquisição de gêneros alimentícios, no mínimo 30\%, oriundos da agricultura familiar como preconiza a legislação, preferencialmente com hortifrutigranjeiros, sendo que em situações adversas, como complicações nos processos licitatórios e de chamada pública, essa parcela, segundo o relato, é preenchida com estocáveis também adquiridos da agricultura familiar.

O relato da RT afirmou que, com a melhoria da organização dos agricultores familiares em associações/ cooperativas, facilitou a aquisição de gêneros alimentícios acima do limite mínimo de $30 \%$. Além disso, contribuiu para superar limitações anteriormente encontradas como a dificuldade nas entregas uma vez que o fornecimento acontece ponto a ponto em cada uma das 64 unidades escolares e mais algumas entidades dentro do município.

O controle de estoque é realizado, a princípio, através da determinação da demanda anual nos processos licitatórios e controlado pelo setor de abastecimento para que seja suficiente durante o ano letivo e no outro ponto, por registro manual dos agentes sociais nas unidades escolares, onde o que é distribuído para a semana é registrado em fichas de estoque para o controle do fluxo e, posteriormente, ser utilizado como elemento para nutrir a elaboração de novos pedidos. Este documento é de guarda permanente pela unidade escolar e constantemente é avaliado para constar a verossimilhança de suas informações.

No Bloco 4 foi avaliado os mecanismos de controle e qualidade dos alimentos.

O município faz a checagem da qualidade dos alimentos desde o processo licitatório, onde são solicitadas amostras dos produtos para comparar com seus respectivos descritivos e demais componentes da legislação, como embalagem, rotulagem, etc. Além disso, o dia a dia, o agente social fica responsável, durante o recebimento, de avaliar se o alimento entregue possui condições aceitáveis de consumo a partir das percepções sensoriais como cor, cheiro e outras características físicas dos alimentos juntamente com a checagem das quantidades e demais informações da entrega.

Segundo o relato, quando ocorrem problemas com o alimento, o mesmo é devolvido ao fornecedor no mesmo ato, ou seja, não permanece na escola, e é feita uma notificação o devido registro e a justificativa. A empresa 
tem o prazo de 24 horas para repor e entregar um novo alimento, caso contrário, ela sofre um desconto no faturamento da nota fiscal. Nesses casos, a alimentação escolar conta com um almoxarifado de alimentos que supre esses casos específicos para que não ocorra desabastecimento na rede de ensino.

Um ponto crítico observado na entrevista reside no fato que o agente social fica responsável pelo recebimento, estocagem, manipulação e distribuição nas unidades escolares sem contar com mecanismos adequados para a verificação de ponto de controle dos alimentos como temperatura, água, ambiente, entre outros preconizados pela legislação.

O município não conta com manuais de boas práticas nas unidades escolares e a justificativa apresentada fica no número reduzido de funcionários e equipamentos como, por exemplo, termômetros disponíveis para realizar as avaliações em todas as etapas desde o recebimento até o consumo final. A orientação se torna mais prática e reforçada no dia a dia e concentrada em aspectos mais gerais e que exigem muito da percepção individual do agente, o que por si só, é pouco para garantir a higiene e adequação do alimento.

Existe a solicitação e análise de amostras dos alimentos tanto nos processos licitatórios onde a checagem ocorre mediante comparação com o descritivo e, a priori, com a preparação da receita e, a posteriori para avaliar a compatibilidade de sua condição durante as visitas técnicas.

Adiante, a introdução de novos alimentos ocorre pela realização do teste de aceitabilidade utilizando os métodos de escala hedônica facial e resto ingestão, de acordo com a legislação, sendo que a mesma não é realizada com menores de 03 (três) anos.

Segundo a entrevistada, pelo número reduzido de funcionários, não existe a possibilidade de realizar um trabalho acerca da avaliação da aceitabilidade como, por exemplo, mudanças nos horários de distribuição porque a formatação atual (almoço, geralmente, às 9:30/10:00 e jantar às 15:00) influencia na aceitação do alunato, resultando num resto ingestão muito alto, principalmente nos dias mais quentes.

O último bloco buscou avaliar as condições de trabalho do CAE. Para tal, a entrevista foi aplicada direitamente aos seus membros.

Segundo os relatos, o CAE está em pleno funcionamento, com regimento interno vigente e com a presença atuante de seus membros. O acompanhamento orçamentário é feito bimestralmente através da apresentação das movimentações financeiras, empenhos e notas, juntamente com o apoio técnico do setor contábil do Executivo.

O CAE participa dos testes de aceitabilidade dos alimentos adquiridos no momento da aquisição e em entrevistas com os alunos. Além disso, realiza visitas técnicas nas UAN utilizando um checklist para verificar as condições de trabalho. Contudo, dada a natureza voluntária da função de Conselheiro, eles têm a dificuldade de ampliar o número de visitas porque a participação fica condicionada a se ausentar de seus locais de trabalho, o que nem sempre é possível. Segundo o relato, no primeiro semestre de 2018 foram realizadas 08 (oito) visitas, sendo que a meta era chegar a 12 (doze), o que não foi atingido.

Contudo, foi possível notar que os conselheiros possuem alguma dificuldade nos aspectos a serem observados nas vistorias realizadas junto aos produtores, o que pode ser ocasionado por um possível desconhecimento sobre a temática das BPA.

O relatório anual de prestação de contas é respondido pelos Conselheiros com base nas visitas realizadas.

Por fim, foi relatado que o CAE conta a disponibilidade de equipamentos, materiais, meios de transporte, recursos humanos e financeiros, inclusive para custear despesas com viagens, para a execução de seus trabalhos. A Secretaria da Educação é atenciosa no atendimento das demandas dos Conselheiros.

\section{Análise da Gestão Local}

Diante dos dados obtidos em campo, organizamos a análise em alguns pontos que concentram aspectos importantes que foram observados sobre a gestão local do PNAE:

$>$ Escassez de recursos financeiros;

$>$ Falta de capacidade em investimentos na infraestrutura, equipamentos e recursos humanos;

$>$ Chamada Pública;

A análise da gestão passa inicialmente pelo estudo das finanças públicas que custeiam a alimentação escolar do Município. Para tal, foram levantados dados da despesa orçamentária, especificamente das ações Aquisição de Gêneros Alimentícios, Apoio à Alimentação Escolar - Educação Infantil e Apoio à Alimentação Escolar - 
Educação Fundamental, obtidos através do Portal da Transparência Municipal, no período de 2014-2018, com dispostos na Tabela 03.

Tabela 03 - despesas com alimentação escolar por ano (em milhões/R\$).

\begin{tabular}{cccccc}
\hline & \multirow{2}{*}{ ORÇADO } & $\begin{array}{c}\text { ORÇADO ATUA- } \\
\text { LIZADO }\end{array}$ & EMPENHADO & LIQUIDADO & \multirow{2}{*}{ PAGO } \\
\hline 2014 & $22.764 .197,00$ & $26.637 .385,89$ & $21.988 .105,07$ & $16.782 .846,79$ & $14.387 .291,08$ \\
2015 & $20.482 .469,00$ & $22.026 .424,33$ & $14.532 .596,76$ & $14.532 .596,76$ & $12.580 .529,16$ \\
2016 & $19.156 .289,00$ & $25.039 .075,60$ & $17.793 .729,07$ & $17.793 .726,24$ & $15.973 .442,50$ \\
2017 & $19.770 .317,10$ & $20.787 .403,14$ & $19.645 .442,24$ & $19.624 .354,08$ & $16.803 .099,47$ \\
2018 & $15.619 .110,22$ & $22.711 .151,23$ & $22.461 .296,82$ & $20.234 .267,41$ & $16.527 .816,00$ \\
\hline
\end{tabular}

Fonte: Prefeitura Municipal de Araraquara (2019).

No primeiro momento, a despesa prevista para a alimentação escolar cai razoavelmente ao longo do intervalo observado. Nota-se que mesmo com a redução na previsão orçamentária, os gastos são crescentes ano a ano.

Para detalhar esse fenômeno, observaremos o comportamento da despesa através da origem do recurso. Basicamente, toda a despesa deve indicar a fonte de recurso que a proverá, sendo ilegal a criação de despesa sem a devida indicação dos recursos. No estudo em tela, dada a natureza da despesa, ela tem como fonte três origens: Tesouro (Fonte 01) que são os recursos de geração própria, ou seja, frutos das receitas municipais; Transferências e Convênios Estaduais - Vinculados (Fonte 02) e Transferências e Convênios Federais - Vinculados (Fonte 05).

Tabela 04 - despesas pagas com alimentação escolar por fonte de recurso (em milhões/R\$).

\begin{tabular}{llll}
\hline & FONTE 01 & FONTE 02 & FONTE 05 \\
\hline 2014 & $8.091 .873,20$ & $2.399 .893,11$ & $3.895 .524,77$ \\
2015 & $9.823 .965,67$ & 0 & $2.756 .563,49$ \\
2016 & $13.014 .640,17$ & 0 & $2.958 .802,33$ \\
2017 & $13.608 .781,02$ & 0 & $3.194 .318,40$ \\
2018 & $13.476 .054,15$ & 0 & $3.051 .761,85$ \\
\hline
\end{tabular}

Fonte: Prefeitura Municipal de Araraquara (2019).

A Tabela 04 aponta que, no período de 2014-2018, a maior parcela do gasto com alimentação escolar foi custeada pelo Município, com alguma participação de recursos advindos de transferências estaduais e federais.

Os gráficos indicam percentualmente a participação dos recursos na composição da despesa: 
Figura 01 - Despesas pagas com alimentação escolar por fonte de recurso em 2014.

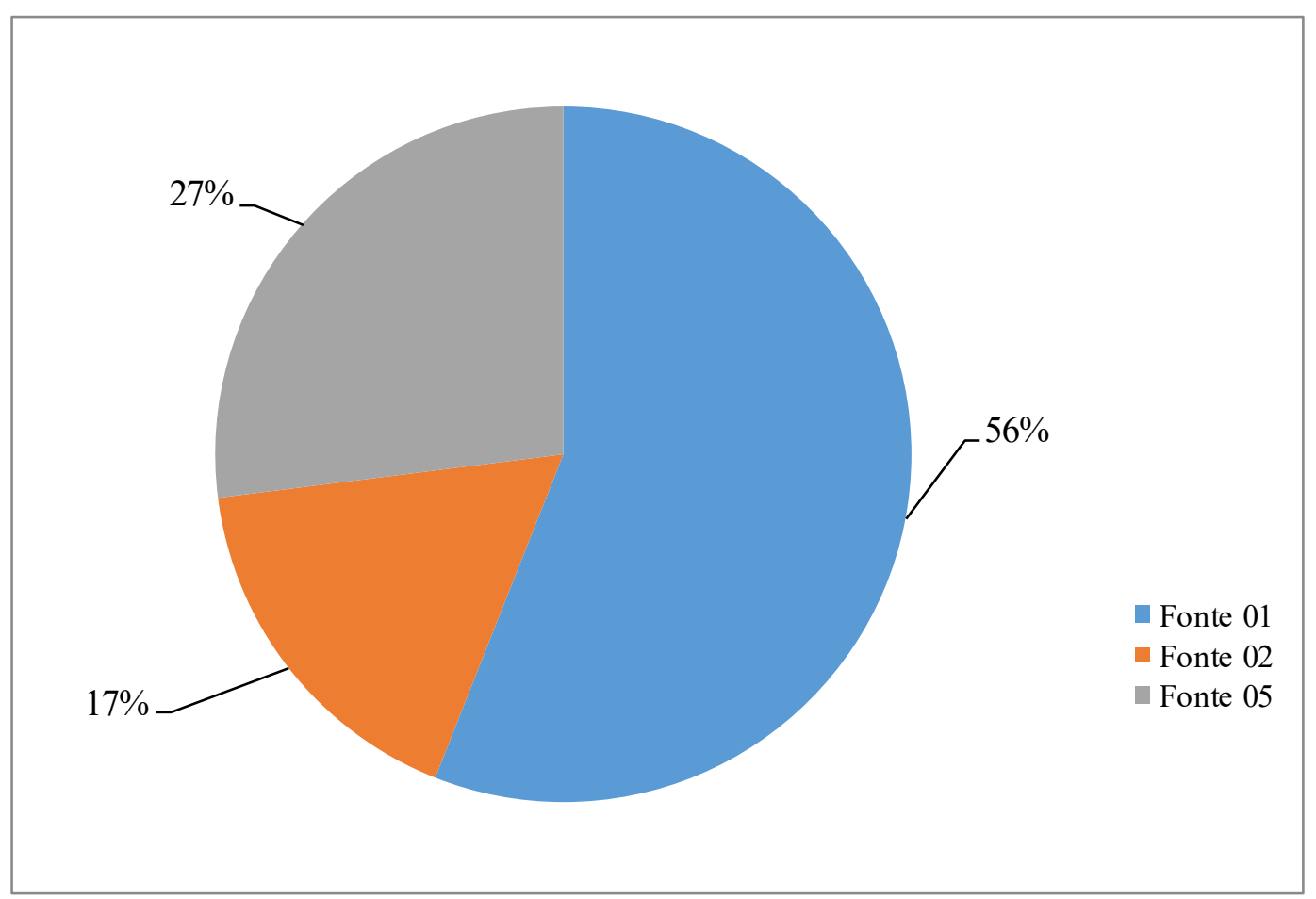

Fonte: Prefeitura Municipal de Araraquara (2019).

Figura 02 - Despesas pagas com alimentação escolar por fonte de recurso em 2015.

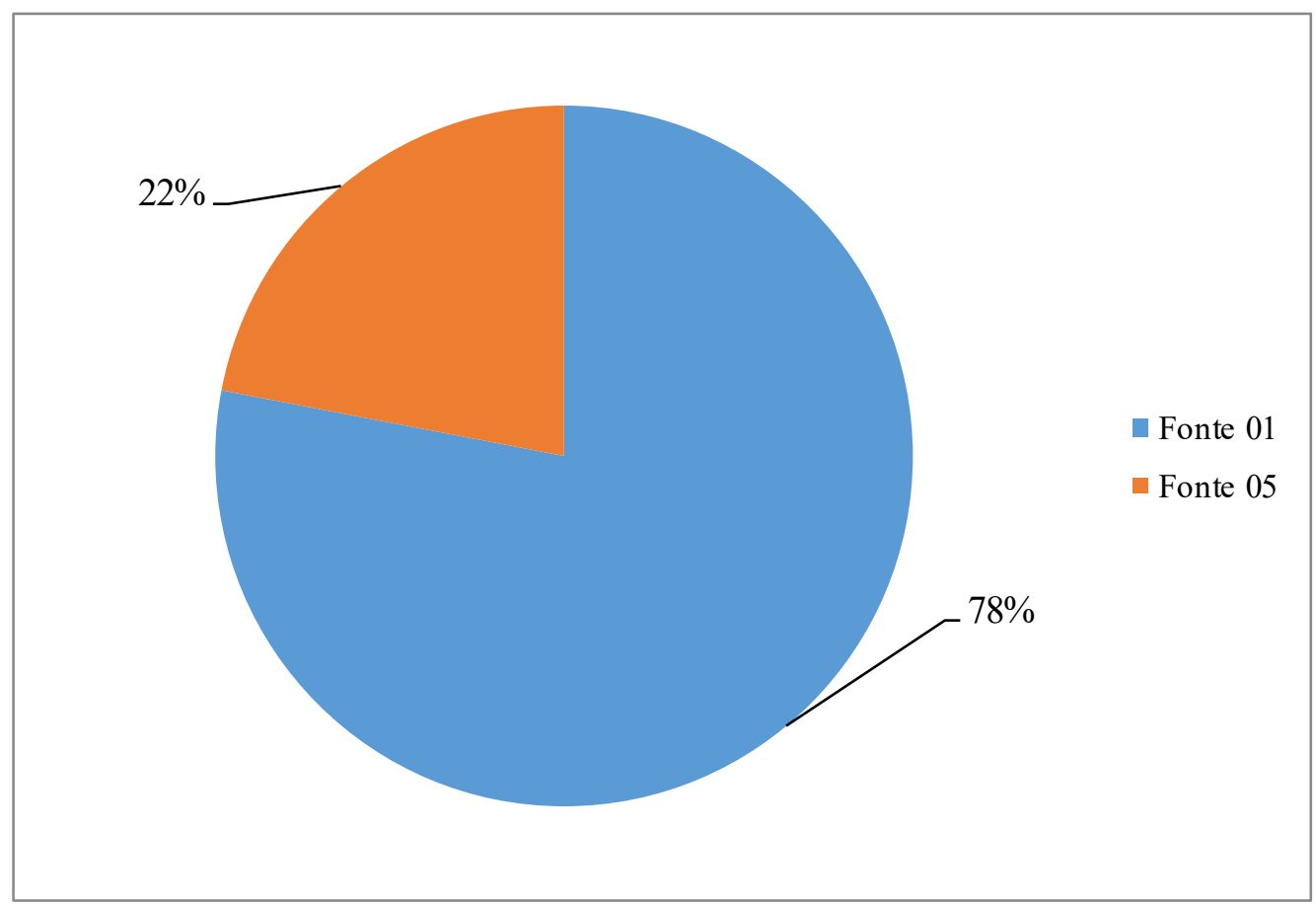

Fonte: Prefeitura Municipal de Araraquara (2019). 
Figura 03 - Despesas pagas com alimentação escolar por fonte de recurso em 2016.

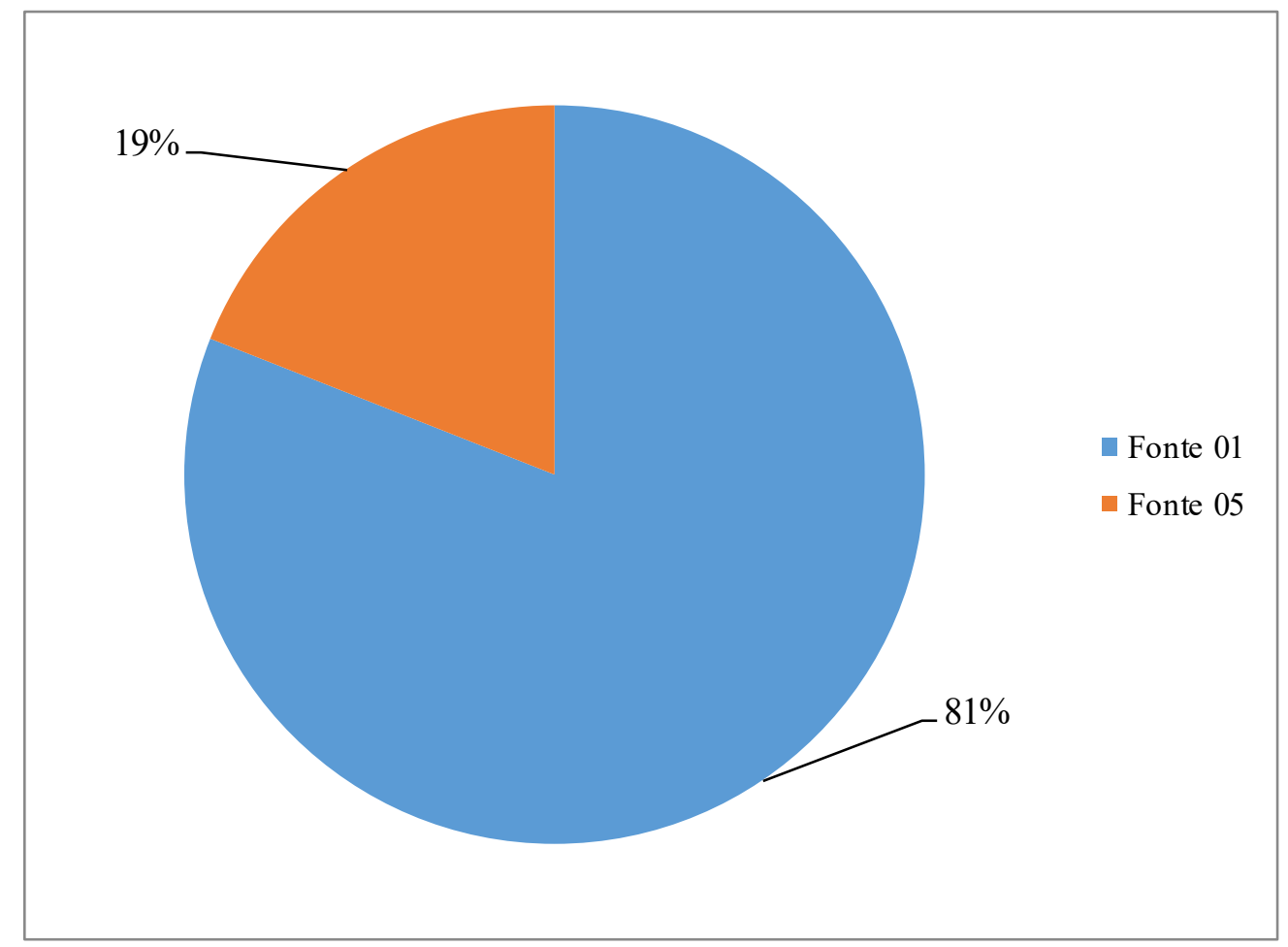

Fonte: Prefeitura Municipal de Araraquara (2019).

Figura 04 - Despesas pagas com alimentação escolar por fonte de recurso em 2017.

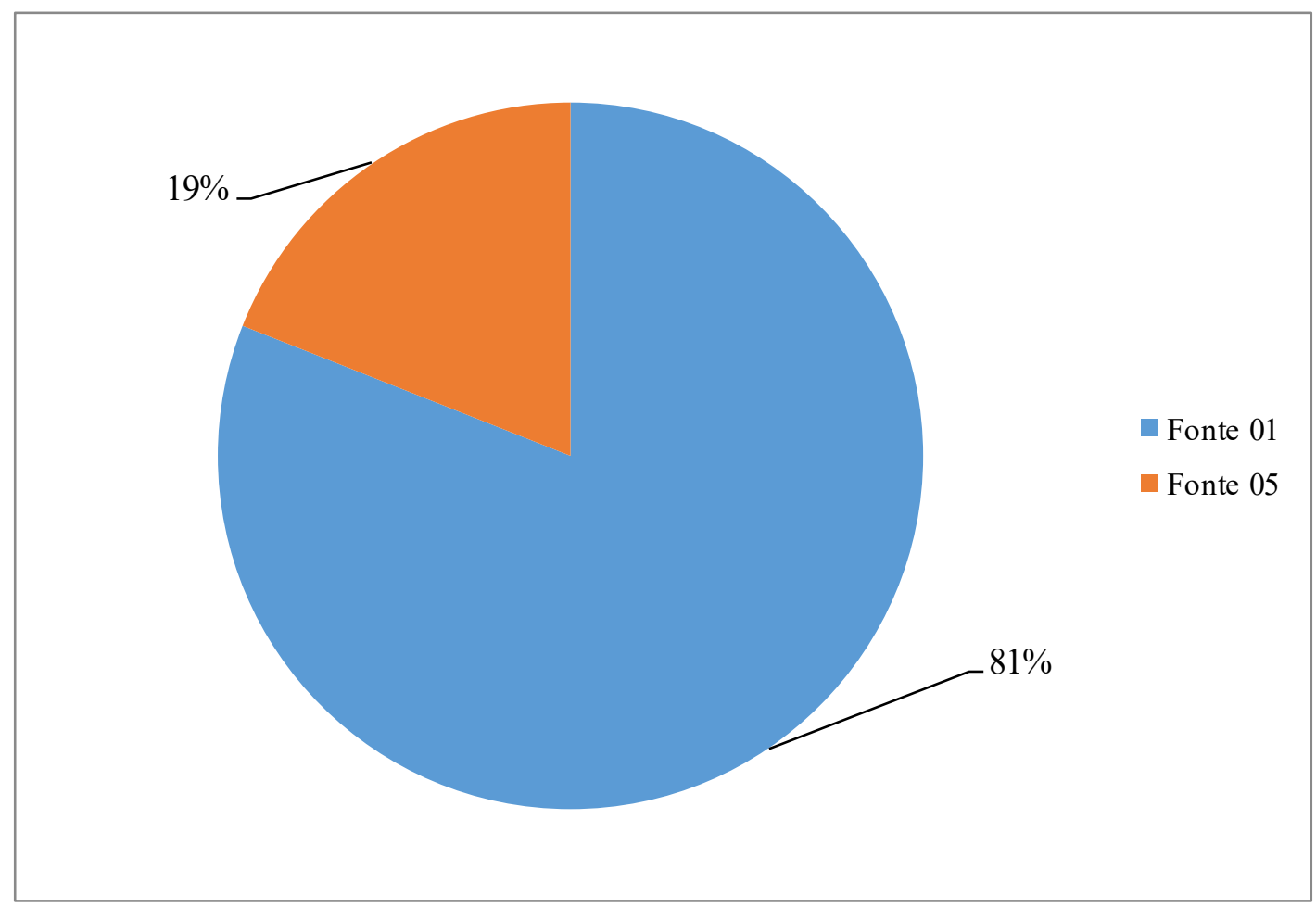

Fonte: Prefeitura Municipal de Araraquara (2019). 
Figura 05 - Despesas pagas com alimentação escolar por fonte de recurso em 2018.

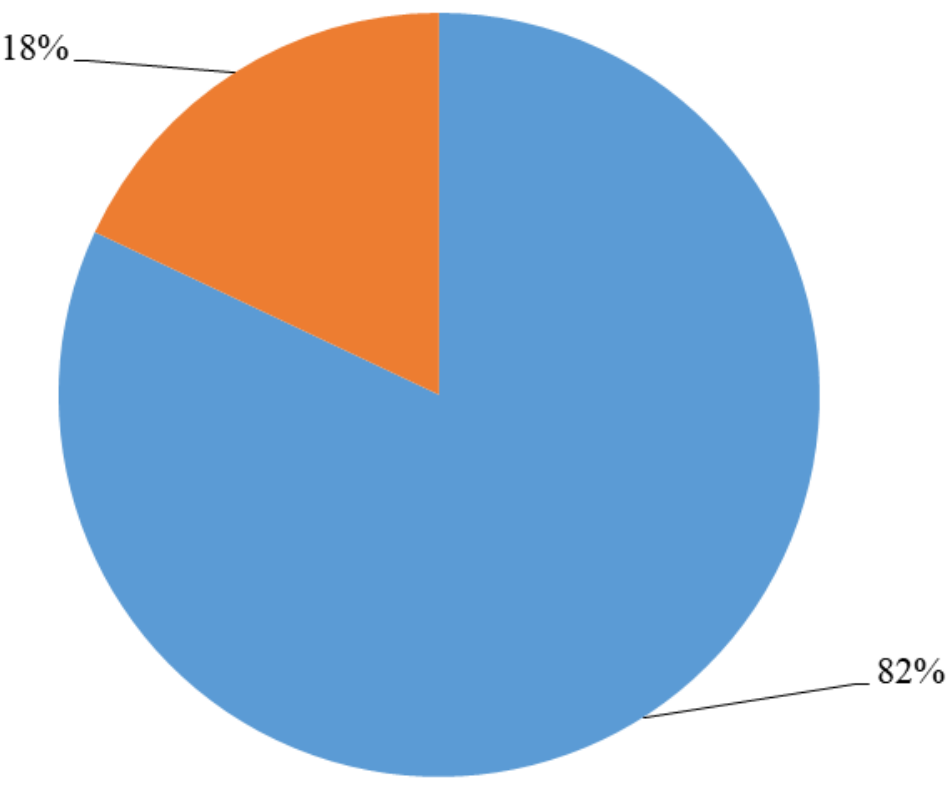

Fonte 01

Fonte 05

Fonte: Prefeitura Municipal de Araraquara (2019).

Pela análise dos gráficos, notamos que o percentual de participação de recursos advindos do PNAE é baixo perante os custos suportados pela gestão municipal.

Figura 06 - Evolução da despesa com alimentação escolar no período 2014-2018.

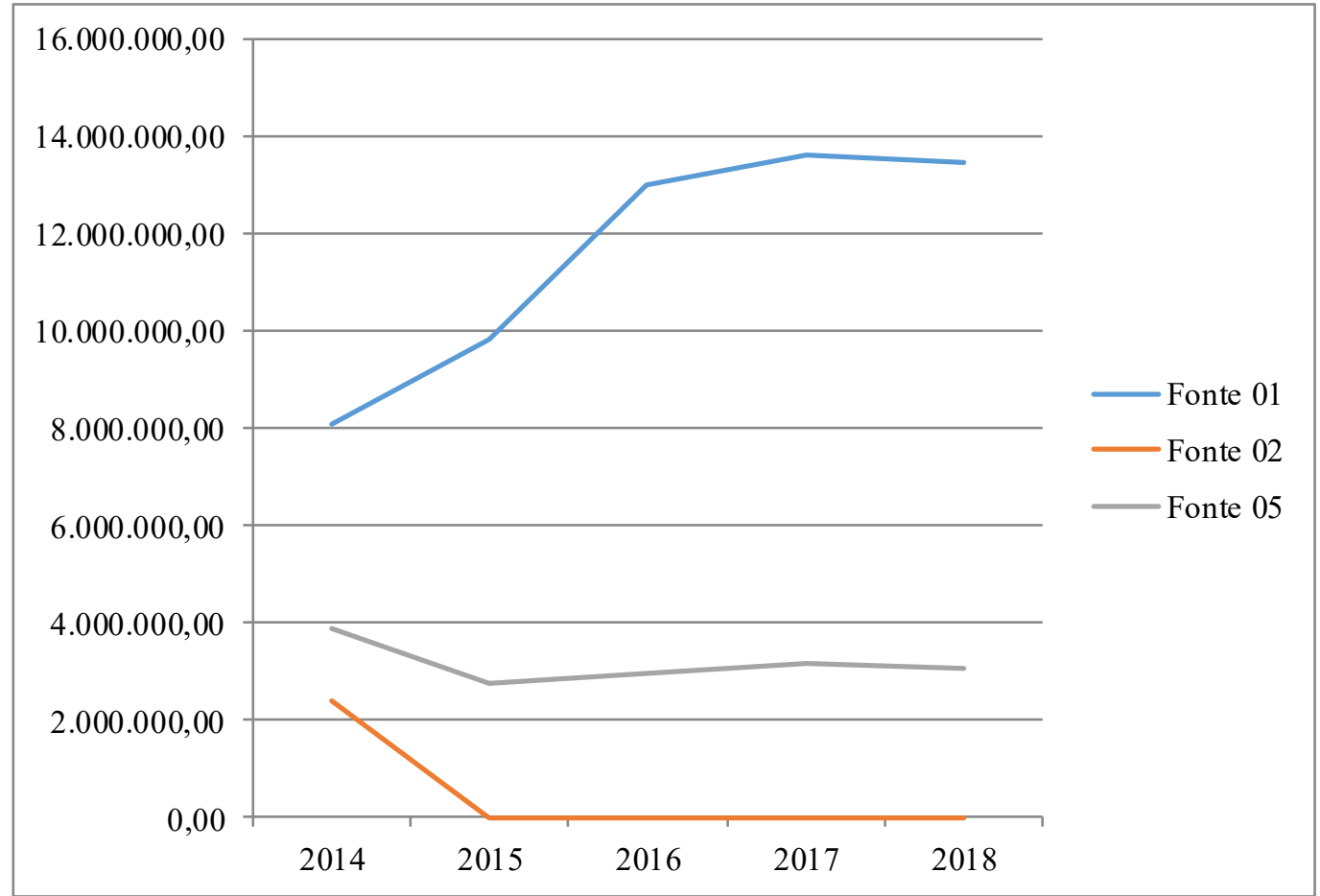

Fonte: Prefeitura Municipal de Araraquara (2019). 
É possível observar que a evolução dos gastos municipais com a alimentação escolar é crescente ao longo do tempo e o volume de recursos vindo de transferências, principalmente federais, manteve-se no mesmo patamar.

Portanto, a escassez de recursos orçamentários relatada na entrevista é concreta e se apresenta como uma dificuldade para a melhoria nos padrões de higiene e adequação.

Este ponto de análise reflete na falta capacidade financeira para realizar investimentos na infraestrutura, equipamentos e recursos. Além disso, foi observado que a gestão possui um número reduzido de funcionários como, por exemplo, nutricionistas, o que dificulta na realização das tarefas de planejamento, execução, fiscalização e controle da política pública. Foi constatado também a falta de equipamentos cruciais, como termômetros, nas UAN tanto pela falta do recurso como de funcionários para sua devida utilização.

O último ponto de discussão sobre a gestão local do PNAE encontra-se na Chamada Pública, mecanismo criado pela Resolução FNDE na 26 de 17 de junho de 2013 e modificado posteriormente pela Resolução FNDE $\mathrm{n}^{\circ} 2$, de 02 de abril de 2015. Nestes dispositivos legais, a legislação determina a forma na qual as Unidades Executoras devem proceder para adquirir gêneros alimentícios da Agricultura Familiar. Neste trabalho, foi estudado a Chamada Pública no 008/2018 - Processo 1005/2018.

O modelo baseia-se na apresentação de projetos de venda elaborados a partir das planilhas disponibilizadas por edital onde constam os produtos e preços máximos de referência para a aquisição dos gêneros alimentícios. Os produtores participam até o limite de $\mathrm{R} \$ 20.000,00$ (vinte mil reais) por Declaração de Aptidão ao PRONAF (DAP) no caso de produtor individual ou grupos informais, ou em grupos formais, no mesmo montante anteriormente citado multiplicados pelo número de agricultores inscritos na DAP jurídica.

O edital conta com alguns mecanismos de fiscalização e controle dos alimentos fornecidos, entre os quais podemos citar a apresentação de Laudo Sanitário de produtos, quando for o caso, sob solicitação da Secretaria Municipal de Educação; Declaração do produtor que autoriza a vistoria da produção por funcionários, membros do CAE ou outro indicado pelo setor responsável e a Declaração do produtor que utiliza defensivos agrícolas de acordo com BPA vigentes. Porém, não foi possível constatar se essas medidas são capazes de assegurar a higiene e adequação dos alimentos.

\section{Apresentação dos Resultados}

Após a análise dos dados, os resultados foram alinhados por blocos e na somatória foi atribuída uma nota de acordo com os seguintes critérios:

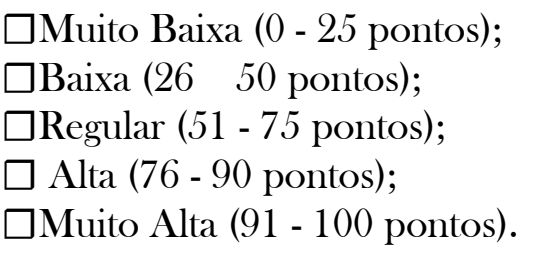

A Tabela 05 aponta os resultados obtidos pela metodologia aplicada:

Tabela 05 - Avaliação da gestão local.

\begin{tabular}{c|c|c|c|c|c}
\hline BLOCO 1 & BLOCO 2 & BLOCO 3 & BLOCO 4 & BLOCO 5 & TOTAL \\
12 & 16,6 & 19 & 24,9 & 14,3 & $\begin{array}{c}86,8 \\
\text { (Alta) }\end{array}$ \\
\hline
\end{tabular}

Fonte: Autor (2019).

Num contexto geral, a gestão local recebeu uma avaliação classificada como alta. Percebe-se que a estrutura organizacional e administrativa é capaz de executar a política pública, na perspectiva da higiene e adequação, de maneira adequada. Existe o cuidado com os cardápios, inclusive nos casos especiais; os alimentos passam por testes de aceitabilidade durante o processo de compra e com o alunato; a aquisição de gêneros alimentícios tem como meta priorizar os produtos orgânicos; a capacitação é tratada como parte importante para o alcance 
de bons resultados.

Contudo, o conceito obtido poderia ser melhor se houvesse capacidade financeira para investimentos na contratação de funcionários e equipamentos para as UAN de modo que a sobrecarga de funções seja reduzida e a fiscalização e controle da produção e manipulação de alimentos fosse feita de maneira mais proativa.

A ressalva reside nos mecanismos que asseguram a higiene e adequação dos alimentos e de fiscalização dispostos na Chamada Pública. Dada a falta de funcionários para as vistorias e, por consequência, a distanciamento entre a gestão e o produtor, o acompanhamento da produção torna-se superficial, o que não permite atestar se as práticas produtivas são positivas.

\section{REFERÊNCIAS}

AGUIAR, A. M. M.; BATISTA, B. V. A.; SANTOS, I. H. V. S.; OLIVEIRA, L. M. L.. Avaliação da Eficácia de uma intervenção sobre as Boas Práticas de Higiene em três lanchonetes de uma escola particular em Porto Velho-RO. SaberCientífico [S.1.], v. 3, n. 1, p. 70-90, nov. 2011.

ASSEMBLEIA GERAL DA ONU. (1948). Declaração Universal dos Direitos Humanos (217 [III] A). Paris. BRASIL. Resolução FNDE no 26, de 17 de junho de 2013 - Dispõe sobre o atendimento da alimentação escolar aos alunos da educação básica no âmbito do Programa Nacional de Alimentação Escolar - PNAE.

CARDOSO, R. C. V.; SOUZA, E. V. A.; SANTOS, P. Q. Unidades de alimentação e nutrição nos campi da Universidade Federal da Bahia: um estudo sob a perspectiva do alimento seguro. Revista de Nutrição, Campinas/ SP, v. 18, n. 5, p. 669-680, Out./2005.

CARVALHO, D. G.; CASTRO, V. M. O Programa Nacional de Alimentação Escolar - PNAE como política pública de desenvolvimento sustentável. Artigo apresentado no VIII Encontro Nacional da ECOECO, Cuiabá/ MT, 2009.

MALUF, R. S.; MENEZES, F. e VALENTE, F. L. Contribuição ao Tema da Segurança Alimentar no Brasil. Revista Cadernos de Debate, v. IV, p. 66-88, 1996.

MARTINS, E. A.; QUARENTEI, S. S. Sistemas de gestão e padrões normativos aplicáveis ao segmento alimentício. In: Sistema de gestão: qualidade e segurança de alimentos. GERMANO, P. M. L.; GERMANO, M. I. S. (orgs). Barueri, SP: Manoele, 2013.

ORTEGA, A. C.; BORGES, M. S. Codex Alimentarius: a segurança alimentar sob a ótica da qualidade. Segurança Alimentar e Nutricional, Campinas/SP, v. 19, n. 1, p. 71-81, fev. 2015.

PAULILLO, L. F. O. E.; PESSANHA, L. Segurança alimentar e políticas públicas: conexões, implicações e regionalização. In: PAULILLO, L. F.; ALVES, Francisco (Orgs.). Reestruturação agroindustrial, políticas públicas e segurança alimentar regional. $1^{\text {a }}$ ed. São Carlos, SP: Edufscar, 2002, v. 1, p. 17-56.

PEIXINHO, A. M. L. A trajetória do Programa Nacional de Alimentação Escolar no período de 2003-2010: relato do gestor nacional. Ciênc. saúde coletiva, Rio de Janeiro/RJ, v. 18, n. 4, p. 909-916, 2013.

SANTOS, A. P. C.; SANTOS, V. F. N. Adequação de Estrutura Física de Unidades de Alimentação e Nutrição na Cidade de São Paulo - SP. Publ. UEPG Ci. Biol. Saúde, Ponta Grossa/PR, v. 22, n. 1, p. 14-20, jan/jun. 2016.

VIEIRA, M. N. C. M.; FERRIANI, M. G. C.; GOMES, R.; SANTOS, G. V. B.; MARCHI, E. M. M. Gestão de um programa de alimentação escolar em um município paulista. Segurança Alimentar e Nutricional, Campinas/ SP, v. 15, n. 1, p. 29-48, fev. 2008. 